\title{
PARTiCipação e património Cultural IMATERIAL: O ESTUDO DE CASO DE “TAVA, LUGAR DE REFERÊNCIA PARA O POVO GUARANI"
}

\author{
Rodrigo Lacerda \\ Faculdade de Ciências Sociais e Humanas, Departamento de Antropologia, Universidade Nova de Lisboa, Portugal
}

\begin{abstract}
Resumo
A categoria de património cultural imaterial $(\mathrm{PCl})$, institucionalizada no início deste século por diversos países (no ano 2000, no caso do Brasil) e, a nível internacional, pela Unesco (2003), exige a participação dos grupos e comunidades detentores dos bens culturais na sua identificação, salvaguarda e manutenção. Devido ao carácter recente destas políticas patrimoniais, ainda existe um número reduzido de estudos que reflitam sobre os níveis e estratégias de participação utilizados no PCI. Mais recentemente, Rodney Harrison (2013) defendeu a importância de não só estudar a participação de humanos nos processos patrimoniais, mas também, nomeadamente, em contextos indígenas, de não humanos. Com o intuito de contribuir para estas discussões, o artigo descreve e analisa a patrimonialização das ruínas da Missão Jesuítico-Guarani de São Miguel, localizadas no estado brasileiro de Rio Grande do Sul, enquanto "Tava, Lugar de Referência para o Povo Guarani". O processo durou uma década e encontrou inicialmente diversas resistências por parte dos Guarani. Contudo, o estabelecimento de relações de reciprocidade e de afinidade entre agentes indígenas e não indígenas, o reconhecimento das potencialidades políticas do $\mathrm{PCl}$ e a influência de aspetos de ordem espiritual, incluindo de não humanos, promoveram a participação dos Guarani, que demonstraram ser atores essenciais para a identificação e registo do bem cultural em 2014.
\end{abstract}

\section{PARTICIPATION AND INTANGIBLE CULTURAL HERITAGE: A CASE STUDY OF “TAVA, PLACE OF REFERENCE FOR THE GUARANI PEOPLE"}

\begin{abstract}
The category of intangible cultural heritage $(\mathrm{ICH})$, recently institutionalized by several countries (2000, in the case of Brazil) and, internationally, by Unesco (2003), requires the participation of groups and communities in the identification, safeguarding and maintenance of their heritage. Due to the recent nature of these policies, there is still only a small number of studies examining the levels and strategies of participation used in determining $\mathrm{ICH}$. More recently, Rodney Harrison (2013) argued that is important to study not only the participation of humans in heritage processes, but also, especially in indigenous contexts, the participation of nonhumans. In order to contribute to these discussions, the article describes and analyzes the patrimonialization of the ruins of the São Miguel Jesuit-Guarani Missions, located in the Brazilian state of Rio Grande do Sul, as "Tava, Place of Reference for the Guarani People". The process lasted a decade and initially encountered some resistance from the Guarani. However, the establishment
\end{abstract}


of reciprocity and affinity relations between indigenous and non-indigenous agents, the recognition of ICH's political potential and the influence of spiritual aspects, including nonhumans, promoted the participation of the Guarani, who proved to be essential actors for the identification and registration of the cultural landmark in 2014.

KEYWORDS

Brazil; dialogical heritage; Guarani; intangible cultural heritage; participation

\section{PARTICIPAÇÃo F PATRIMónio CULTURAL IMATERIAL}

A categoria de património cultural imaterial $(\mathrm{PCl})$ foi institucionalizada no início deste século a nível internacional através da Convenção para a Salvaguarda do Património Cultural Imaterial da Unesco, em 2003, e, a nível nacional, no Brasil, em 2000, através do Programa Nacional de Património Imaterial (PNPI), coordenado pelo Instituto do Património Histórico e Artístico Nacional (IPHAN). Ao contrário do património material, o $\mathrm{PCl}$ só pode ser registado e salvaguardado se fizer parte da vida ativa de grupos e comunidades. Por esta razão, a legislação nacional e internacional do PCl introduz inovações significativas ao reconhecer o papel determinante da participação de grupos e comunidades na produção, identificação, salvaguarda, manutenção e recriação do $\mathrm{PCl}$ (Blake, 2009). Esta inovação também advém das críticas às políticas do património material que é exclusivamente regulado pelo Estado e especialistas científicos (experts) (Harrison 2013; Smith, 2006) e da necessidade de desenvolver políticas de "baixo para cima" que reconheçam os conhecimentos e vivências dos detentores do património (Herzfeld, 1991). Esta abordagem tem vindo a revelar-se cada vez mais importante na manutenção da dissonância inerente ao património, nomeadamente em sociedades plurais (Ashworth, Graham \& Turnbridge, 2007; Ashworth \& Turnbridge, 1996). De qualquer modo, tal como noutros contextos (Cooke \& Kothari, 2004), o recurso à participação no $\mathrm{PCl}$ também tem sido criticado devido aos riscos da sua instrumentalização pelo Estado ou determinados atores das comunidades e por causa dos perigos de essencializar e reificar conceitos como grupo, comunidade e cultura (Bortolotto, 2014; Noyes, 2006).

Contudo, a nível institucional e na maioria dos estudos sobre este tema, a participação no $\mathrm{PCl}$ tem sido somente equacionada a nível da ação de humanos. Recorrendo às obras de Bruno Latour e Eduardo Viveiros de Castro e ao seu trabalho com povos aborígenes na Austrália, em Heritage: critical approaches, Rodney Harrison (2013) expande a ideia de participação numa perspetiva construtivista no sentido de incluir a participação de não humanos e coisas e propõe o conceito de "património dialógico". De acordo com esta tese, o património não é constituído através da atribuição de significado pelas mentes humanas a objetos e práticas, mas emerge de um modo interativo e mutuamente constitutivo pelas relações estabelecidas e continuamente reconstruídas entre humanos e humanos, humanos e não humanos e entre estes e coisas. Este modo de pensar o mundo rompe com as divisões cartesianas mente/corpo, natureza/cultura e humanos/ 
não humanos e assenta numa "ontologia de conectividades" que nos obriga a analisar como as conexões entre diferentes elementos constroem o todo. Como argumenta Deborah Bird Rose (2011), "a ética da conectividade é aberta, incerta, atenta, participativa, contingente. Somos chamados a agir, a envolvermo-nos nos dramas de pergunta e resposta, e a fazê-lo com base naquilo que se nos apresenta no curso da vida" (Rose, 2011 , p. 143). Harrison defende ainda que a expansão do conceito de participação pode promover a constituição de "fóruns híbridos" em que os atores especialistas e não especialistas, humanos e não humanos participem na construção do património de modo a fomentar uma "democracia dialógica". Em suma, se o património é ontologicamente dialógico, é essencial compreender, como examinaremos neste artigo a participação e a mútua influência entre si de humanos (especialistas científicos e não científicos), não humanos e coisas.

Nesse sentido, o artigo tem como objetivo compreender como o $\mathrm{PCl}$ emerge através das relações entre estes diversos atores, descrevendo e analisando o estudo de caso da patrimonialização pelo IPHAN das ruínas da Missão Jesuítico-Guarani em São Miguel enquanto "Tava, lugar de referência para o povo Guarani". Atualmente, os Guarani habitam uma área extensa da América do Sul, incluindo Argentina, Paraguai, Uruguai e regiões sul e sudeste do Brasil. Aqueles que vivem neste país dividem-se em três grupos: Kaiowá, Ñandeva e Mbya. Esta classificação foi proposta por Schaden (1974, p. 2) com base em diferenças linguísticas e culturais, mas também é reconhecida pelos indígenas, apesar do uso dos etnónimos poder divergir, como é comum no caso das classificações nativas (Castro, 2002a). No artigo, tal como os próprios, alterna-se entre os termos "Guarani", "Mbya" e "Mbya-Guarani". Em termos metodológicos, o trabalho recorreu à observação etnográfica junto dos Mbya-Guarani e outros atores, como a Organização não Governamental (ONG) Vídeo nas Aldeias, a entrevistas com participantes indígenas e não indígenas e à pesquisa de arquivo.

\section{As Missões Jesuítico-Guarani e os Guarani Que nunCa Partiram}

As ruínas da catedral de São Miguel fazem parte das Missões Jesuítico-Guarani construídas durante os séculos XVII e XVIII no cone sul da América sob domínio espanhol. O objetivo das Missões era "civilizar" e catequizar os povos indígenas, maioritariamente Guarani, de modo a assimilá-los enquanto sujeitos "produtivos" do Império (Ganson, 2003). Em 1750, Portugal e Espanha assinaram o Tratado de Madrid que atualizou o Tratado de Tordesilhas e que determinou que o primeiro transferia a Colónia de Sacramento para o segundo em troca do território que corresponde hoje aproximadamente aos estados do sul e interior do Brasil. No século XX, estas estruturas em São Miguel foram classificadas como património pelo Estado-nação (1938) e pela Unesco (1983). Em ambos os casos de patrimonialização, a dimensão supostamente civilizadora da Companhia de Jesus foi enfatizada e a contribuição e a agência dos indígenas ignoradas'.

\footnotetext{
'Para uma análise mais detalhada dos discursos e imagens patrimoniais produzidas por não indígenas sobre as Missões Jesuítico-Guarani, consultar “O plano, o contraplano e o 'plano sem plano': imagens ocidentais e os Mbya Guarani das Ruínas de São Miguel” (Lacerda, 2018a).
} 
Até recentemente, a histografia e os discursos patrimoniais sustentavam que as Missões sob comando português tinham sido rapidamente abandonadas e que os indígenas se tinham misturado com a restante população migrante da região. Contudo, estudos recentes, incluindo pesquisas desenvolvidas durante o processo do $\mathrm{PCl}$ em análise neste artigo, indiciam que as estruturas continuaram a ser utilizadas até meados do século XIX e que parte da população indígena se refugiu em locais distantes da colonização, continuando a visitar com frequência as ruínas das Missões (Batista, 2015). Nos anos 1990, um grupo de Mbya-Guarani estabeleceu-se com maior permanência em São Miguel. No ano 2000, através da intervenção de diversos aliados não indígenas dos Mbya, o Governo do Estado de Rio Grande do Sul comprou a área da Reserva Indígena Inhacapetum onde aquele grupo fundou a aldeia de Tekoa Koenju. Devido à dimensão reduzida da reserva, os indígenas continuam a vender artesanato no Parque Arqueológico de São Miguel para poderem comprar alimentos e outros produtos de subsistência (Lacerda, 2018a).

\section{InVentáRio NaCional de ReferênCIAS Culturais}

O PNPI estabeleceu o Registo de Bens Culturais de Natureza Imaterial e o Inventário Nacional de Referências Culturais (INRC) enquanto metodologia de mapeamento daqueles. O INRC é constituído pelas seguintes etapas: levantamento preliminar; identificação; e documentação. A superintendente do IPHAN de Rio Grande do Sul (IPHAN-RS) (2003-2013), Ana Lúcia Meira, propôs a aplicação deste instrumento junto das populações minoritárias do estado que não tinham sido contempladas nos processos de património material. Tendo em conta que a catedral de São Miguel é um dos principais símbolos daquele estado e que a presença dos Mbya a vender artesanato no alpendre do Museu gerava controvérsia no IPHAN, Meira, em conjunto com a colega historiadora Beatriz Muniz Freire e a antropóloga do IPHAN central, Ana Gita Oliveira, decidiram implementar o INRC junto desta população. Nesse sentido, o órgão governamental estabeleceu um protocolo com a Universidade Federal do Rio Grande do Sul (UFRGS) com o intuito de contratar uma equipa de antropólogos. Este grupo foi liderado por Catafesto de Souza que já tinha desenvolvido trabalhos nas áreas de arqueologia e antropologia em São Miguel, nomeadamente com a população Guarani (Souza, 1998).

Logo nas primeiras reuniões, Catafesto de Souza avisou o IPHAN que os Guarani são um povo reservado devido às perseguições coloniais e racistas que sofreram e sofrem e porque a convivialidade com os jurua, isto é, os não indígenas, é perigosa em termos cosmológicos para o seu bem viver (Pierri, 2018; Pissolato, 2007). Porém, nos últimos anos, devido à consagração dos direitos indígenas na Constituição de 1988, os Guarani tinham iniciado um processo de abertura à sociedade civil com o objetivo de lutarem contra o racismo de que são alvo e de reivindicarem a demarcação das suas terras, recorrendo a políticas de objetivação da cultura (Handler, 1988) ou "cultura com aspas" (Cunha, 2008), tais como a edição de um CD de música e apresentações regulares do coral de crianças na praça do Mercado Público de Porto Alegre, capital do estado (Pires, 2007). Apesar de os Guarani serem um dos povos mais numerosos no Brasil e terem 
uma presença continental, as terras demarcadas são diminutas e aquelas que foram compradas pelos estados, como a de Inhacapetum, não são reconhecidas enquanto tal pela Fundação Nacional do Índio (FUNAI). Além dos problemas transversais aos povos indígenas no Brasil, esta situação é exacerbada pela intensa colonização agropecuária no sul do país que afastou os Guarani para as cada vez mais reduzidas áreas de mata, por vezes do outro lado da fronteira ou, como dizem os Mbya, que não aceitam os limites territoriais impostos pelas nações, "do outro lado do rio". Esta conjuntura leva a que a sociedade nacional os denomine "estrangeiros", "argentinos" ou "paraguaios" e não Ihes reconheça o direito à terra.

Por estas razões, apesar da desconfiança provocada pelo súbito interesse do estado, isto é, do IPHAN, em os querer ouvir agora, após séculos de colonização e racismo, os Guarani aceitaram participar no INRC quando identificaram na nova categoria instituída pelo Estado, o património, as potencialidades políticas deste para reivindicarem os seus direitos fundiários. Mesmo assim, ao compreenderem a incapacidade do IPHAN em lidar com estas questões, exigiram sempre a presença de representantes da FUNAI nos encontros organizados durante o INRC. No sentido de garantir o envolvimento dos Guarani e estabelecer relações de reciprocidade e afinidade entre agentes indígenas e não indígenas, o IPHAN-RS promoveu e financiou vários encontros de Guarani de diversas aldeias e antecipou algumas medidas de salvaguarda do $\mathrm{PCl}$ [por exemplo, apoio financeiro e logístico a rituais de nomeação (nheemongarai), a construção de casas de reza $[o p y]$ e a oficinas de formação de cineastas indígenas].

A equipa de antropólogos enfrentou outros dilemas no terreno. Segundo a documentação oficial do PNPI, o PCI deve ser detido por uma comunidade de um determinado "sítio". Contudo, os Guarani caracterizam-se por um modo de vida de multilocalidade (Pissolato, 2007), isto é, por viajarem com frequência entre aldeias para, como eles dizem, "visitar os parentes", e por mudarem várias vezes de local de residência ao longo da vida ${ }^{2}$. Além disso, a unidade sociopolítica dos povos indígenas das terras baixas da América do Sul não é, ao contrário do que o senso comum advoga, a aldeia, mas a família extensa, constituída pelas redes de afinidade construídas através do casamento, comensalidade e convivialidade. Nesse sentido, como a equipa de antropólogos argumenta no relatório da etapa de identificação (INRC, 2006) e outros indícios apresentados mais à frente substanciam ${ }^{3}$, a tradução mais apropriada do conceito de comunidade para o modo de vida Guarani incluiria todos os indivíduos deste povo que vivem em diversas aldeias e estados.

De qualquer modo, num momento inicial, o estudo foi realizado com as pessoas que vivem no sítio delimitado pelo INRC: as ruínas, onde os Mbya vendem o artesanato, e a aldeia de Tekoa Koenju, onde aquelas moram. Porém, devido à exiguidade atual das

\footnotetext{
${ }^{2}$ Esta mobilidade também assenta no ethos Guarani de seguir a conduta das divindades que, como o sol (Kuaray), todos os dias traz luz e vida no seu percurso de leste (onde mora Nhanderu Tenonde) a oeste (onde visita o deus Tupã).

${ }^{3}$ A exigência da expansão do INRC às outras aldeias Mbya no Brasil, Argentina e Paraguai durante o "I Encontro Povos Indígenas e o Patrimônio: os Mbya-Guarani e as Missões" e a proposta de registar a Tava como pertencente a todos os Guarani e não exclusiva dos Mbya.
} 
terras indígenas, é frequente uma aldeia estar dividida politicamente em diversas famílias extensas. Segundo a antropóloga Daniele Pires (2007), da equipa do INRC:

do ponto de vista político, a aldeia encontrava-se, na época da pesquisa, dividida em dois grupos: os que apoiavam o então cacique Floriano Romeu (Verá Xondaro) em suas práticas de cooptar-se com políticos da região, aceitar recursos deles em troca de votos dos indígenas, de não dividir com todos os recursos destinados a toda comunidade etc.; e os que se revoltavam e posicionavam-se contra o cacique e seus apoiadores devido a estas práticas. Estes últimos se diziam mais voltados ao Mbyá rekó no modo de tratar o povo, não tendo interesse em acumular dinheiro, procurando estar sempre próximos a Nhanderu (deus/nosso pai), afirmando que a ganância por dinheiro é coisa do juruá e que o Mbyá que entra nesse jogo está se afastando de Nhanderu, está perdido, está doente. (Pires, 2007, p. 96)

Assim, como sintetizou Carlos Moraes, outro antropólogo da equipa do INRC, "o que estava posto, em verdade, era uma disputa entre duas famílias extensas, que, devido à falta de espaço, eram obrigadas a ocupar e dividir a mesma área" (Moraes, 2010, p. 35). Durante o INRC aconteceu um caso que desvelou este problema. A certa altura, Catafesto de Souza requisitou ao IPHAN que os principais interlocutores Mbya fossem pagos como pesquisadores. Uma vez que estes não possuíam um cadastro de pessoa física (CPF) ${ }^{4}$, foi fornecido o número de outro Mbya, que deveria endossar o pagamento àqueles, mas que não o fez. Catafesto de Souza dirigiu-se à aldeia para resolver a situação, mas foi impedido de entrar. A partir daí, a pesquisa ficou suspensa naquele espaço. Por outro lado, o relatório do INRC (2006, p. 8) não menciona aquele episódio e faz referência a "uma série de contradições, geradas pela dúvida em torno aos benefícios advindos da aplicação do INRC", que teriam sido causados por agentes externos e que culminaram na substituição de cacique por causa de ingerências de partidos políticos em ano de eleições. Devido a este obstáculo, a equipa do INRC estendeu o projeto a outras aldeias com as quais tinham afinidade devido a projetos desenvolvidos em conjunto com a UFRGS e com o cacique José Cirilo (ver mais à frente). Este facto foi detetado pelos funcionários do IPHAN que tentaram estender aquele universo durante os encontros que realizaram, convidando outros representantes Guarani e ONG indígenas e indigenistas [como a Comissão Guarani Yvyrupa (CGY) e o Centro de Trabalho Indigenista (CTI)].

A segunda etapa do INRC sofreu um atraso de cinco meses devido a "contingências administrativo-financeiras" que originaram algumas consequências negativas, como perda de alguns eventos Guarani, quebra na interação quotidiana e, acima de tudo, desmobilização dos interlocutores Mbya. Devido à continuação de problemas políticos internos na Tekoa Koenju, em agosto de 2005 a equipa do INRC pediu a José Cirilo, cacique da Tekoá Anhetenguá, a aldeia Mbya mais perto de Porto Alegre, que é

\footnotetext{
${ }^{4}$ Equivalente ao número de identificação fiscal em Portugal.
} 
nomeado por alguns, como Mburuvixá Tenondé Cacique-Geral no Rio Grande do Sul5, para os acompanhar e interceder junto das pessoas da aldeia. Cirilo nasceu em 1974 na Argentina e mudou-se para o Brasil quando era muito novo. Eventualmente, assentou na Lomba do Pinheiro, onde fundou a Tekoá Anhetenguá (Aldeia Verdadeira) e um coral de crianças que faz apresentações em Porto Alegre e outras localidades. A sua mãe, kunha karai ${ }^{6}$ Ana Pires, e seu irmão, karai Augustinho Duarte, ambos importantes líderes espirituais, são as suas principais influências e, por isso, Cirilo "se apresenta como porta-voz da tradição e conta com aprovação de muitos velhos, adultos, mulheres e crianças Mbyá" (Pires, 2007, p. 124). Por outro lado, também aprendeu desde cedo a colaborar com projetos estatais e ONG no sentido de constituir aliados para a luta pelos direitos do seu povo, apesar de também as criticar. Como explica Pires (2007, pp. 131-132), orientanda de mestrado do próprio Cirilo, este

[d]iferencia-se de grande parte das lideranças indígenas brasileiras, porque não luta pela igualdade e nem concorda com o discurso recorrente que diz que um dia os índios vão se tornar políticos e presidentes. Para ele, o objetivo é consolidar o reconhecimento da diferença cultural de seu povo, onde não existem escola, igreja, partidos políticos e saúde como categorias separadas do resto da vida; e ao mesmo tempo defender a igualdade no atendimento a seus direitos, mas diferenciados, específicos. (Pires, 2007, pp. 131-132)

Cirilo acedeu ao pedido da equipa de antropólogos e, no primeiro dia em São Miguel, visitou a casa onde os Mbya dormem no Parque Arqueológico quando estão a vender artesanato e não podem regressar à aldeia. Estes queixaram-se da falta de condições da estrutura, como ausência de canalização de água e instalação elétrica. À noite, assistiu ao Espetáculo de Som e Luz que é realizado diariamente desde os anos 1970 e que se baseia na narrativa patrimonial romântica na qual os padres jesuítas lutaram pela salvação terrena e espiritual dos Guarani. No dia seguinte, comunicou à equipa que tinha sonhado com Sepé Tiaraju, líder mítico dos Guarani das Missões, e que isso era um sinal dos deuses para ele se envolver com o projeto do INRC. Segundo relato de Cirilo incluído no dossiê do INRC:

naquela noite, em São Miguel, depois de ter circulado pelas Ruínas e assistido ao Show de Som e Luz - que me chocou muito, não contive as lágrimas pensando no porque de somente os brancos estarem contando a História de Sepé e do povo Guarani - fui dormir com estas imagens na cabeça. Primeiramente, avistei somente um morro. Forçando o olhar vi a pessoa Guarani mesmo, vestindo apenas tambeó [tanga], eu queria apertar na mão dele. Ele falou: sou Sepé e eu estou vivo! Havia muitas pedras na subida do morro onde ele estava. Além das pedras a terra era muito escorregadia e ninguém podia tocar nele. Os mais velhos Karaí já tinham dito

\footnotetext{
${ }^{5} \hat{E}$, contudo, importante frisar que esta categoria não existia anteriormente e não é encontrada em nenhum estado do Brasil.

${ }^{6} \mathrm{O}$ pajé ou xamã Mbya-Guarani masculino é denominado karai e o feminino kunha karai.
} 
que Sepé não estava morto, mas eu não acreditei. (...) Este trabalho surgiu com a orientação do Sepé, com a verdade. (INRC, 2006)

Esta experiência marcou a entrada definitiva de Cirilo no projeto do $\mathrm{PCl}$ e uma maior abertura do cacique da Tekoa Koenju.

Em 2006, a equipa do INRC organizou o "I Encontro Povos Indígenas e o Patrimônio: os Mbyá-Guarani e as Missões" com o objetivo de discutir o processo do INRC. Cirilo traduziu o evento por "Nhemboaty Mbyá Kurey Tava Miri py São Miguel Arcanjo" e, pela primeira vez, os antropólogos descobriram que existia um nome Guarani para designar as ruínas: Tava Miri. Etimologicamente, tava advém de pedra (ita) e pessoa (ava) e pode ser traduzida como "casa de pedra" ou "aldeia de pedra". Miri significa perfeito e celestial, tal como em Nhanderu Miri, aqueles que chegaram à Terra sem Males (a morada celeste imperecível). Esta perspetiva sobre as Missões tinha sido transmitida a Cirilo pela sua mãe e pelo seu irmão, mas aquele considerava importante realizar o encontro para ouvir as vozes das restantes lideranças espirituais e decidir a validade desta proposição. Nesse sentido, Cirilo requisitou recursos para "viagens de mobilização" às aldeias para realizar o convite pessoalmente, incluindo não só as lideranças políticas e espirituais, mas também jovens, mulheres, velhos e crianças. Por outro lado, Beatriz Freire, do IPHAN, admitiu que tiveram dificuldade em contactar as restantes aldeias, nomeadamente aquelas que não possuíam ligação ou não eram aliadas de Cirilo.

O encontro decorreu de 3 a 7 de dezembro de 2006. A ideia inicial era pernoitar na Tekoa Koenju, mas os visitantes optaram por se instalar perto das ruínas, recorrendo ao terreno em redor da casa de passagem. Durante os dias 4 e 5, os Mbya visitaram Tekoa Koenju e discutiram entre si diversos temas. Os dias 6 e 7 foram dedicados ao debate com as organizações não indígenas envolvidas, especialmente o IPHAN. As discussões foram assim organizadas do modo que Cirilo considera mais adequado (Moraes, 2010): primeiro a nível intraétnico, depois interétnico. Durante o encontro, várias lideranças exigiram que o INRC fosse expandido a todos os Guarani, incluindo aldeias noutros estados brasileiros, na Argentina e no Paraguai. O IPHAN conseguiu implementar a primeira fase do INRC, coordenado, neste caso, pelo CTI, nas restantes aldeias do Brasil, mas a remuneração e a metodologia não foram consideradas apropriadas por nenhum proponente de forma a continuar o processo para as etapas seguintes. A nível internacional, o Brasil apresentou a proposta de um programa transfronteiriço de inventário com os Guarani na reunião de $\mathbf{2 0 0 6}$ do Centro Regional para a Salvaguarda do Patrimônio Cultural Imaterial da América Latina (CRESPIAL) que, contudo, deu origem a poucos resultados concretos?

\section{A “DIMENSÃo DO MISTÉRIO”: FRONTEIRAS ÉTNICAS DA NÃO PARTICIPAÇÃo}

No final da segunda fase do INRC, a equipa entregou um relatório ao IPHAN-RS onde enunciava críticas e propunha os bens culturais a serem patrimonializados. Em

\footnotetext{
${ }^{7}$ Retirado de http://www.crespial.org/pt/Proyectos/index/0003/inventario-del-universo-cultural-guarani
} 
relação às críticas, além de algumas questões já mencionadas, o documento alertava para o aspeto burocrático, demasiado esquematizado, superficial e pouco holístico das fichas de identificação que eram inapropriadas para compreender a complexidade, interligação e dinâmica da cultura, especialmente tendo em conta a alteridade radical dos povos indígenas (Castro, 2002a).

Em relação aos bens culturais a serem patrimonializados, o relatório apresenta as seguintes propostas: 1) a "dimensão do mistério"; 2) "acesso às áreas de mata"; 3) "reconhecer oficialmente o direito de exercício da 'territorialidade livre"" (INRC, 2006, p. 27). De acordo com as classificações institucionais que, no caso do Brasil, estão divididas nos livros de registo em "saberes", "celebrações", "formas de expressão" e "lugares", as propostas da equipa do INRC são sui generis e revelam uma tentativa de utilizar o relatório para chamar à atenção para as principais preocupações cosmopolíticas dos Guarani, o que não foi considerado adequado pelo IPHAN.

Contudo, para o tema em debate neste artigo é interessante analisar a proposta de patrimonializar a "dimensão do mistério". Em primeiro lugar, este elemento refere-se aos limites conscientes de comunicação que a equipa experienciou no terreno, incluindo a não divulgação de aspetos da sua cultura que os Mbya consideram perigoso gravar e divulgar para os jurua (como os cantos sagrados recebidos de Nhanderu) e a proibição de registo áudio e/ou visual ou mesmo de assistir a certos eventos (por exemplo, nheemongarai). Estas fronteiras são, contudo, fluidas, constantemente em negociação e mudam de aldeia para aldeia ou mesmo de pessoa para pessoa. Por exemplo, no Rio Grande do Sul e na Argentina é proibido filmar dentro da casa de reza (opy) enquanto em São Paulo e Rio de Janeiro tal é permitido.

Em segundo lugar, estas fronteiras também são políticas e étnicas. Certos elementos, como Cirilo, consideram que os Mbya devem primeiro discutir entre eles e, depois de chegarem a um consenso, transmitirem as suas opiniões e reivindicações aos jurua. Por exemplo, os encontros mencionados acima foram constituídos por rodas de conversa dos Mbya nos primeiros dois dias e discussão com os órgãos estatais nos dias seguintes. Esta abordagem permitiu, por um lado, construir uma coesão étnica e, por outro, evitar a exploração, por elementos exteriores, de divergências e fraturas dentro do grupo. Porém, esta conduta também favoreceu os Mbya que são interlocutores privilegiados com a sociedade brasileira. Em suma, tal como vários autores (Clastres, 1974/2013; Pissolato, 2007) defendem, o poder Guarani é intrinsecamente polvilhado de diversos focos (líder político, líder espiritual, famílias extensas, etc.) e o estado deve promover e aceitar o processo de discussão interna que pode demorar anos.

Por fim, existe um cansaço dos Mbya em relação ao trabalho dos antropólogos nas aldeias, especialmente em projetos curtos de ONG, órgãos governamentais e de pesquisas de licenciatura e mestrado que não respeitam o modo de viver do povo, "só fazem perguntas" e não produzem um retorno substancial para a comunidade.

Em suma, como E-J Milne (2012) argumenta, a não participação, ou o estabelecimento de limites à participação, também é uma forma de participação que, além de

\footnotetext{
${ }^{8}$ Retirado de http://portal.iphan.gov.br/pagina/detalhes/122
} 
permitir a proteção dos (não) envolvidos, constitui uma demonstração de poder e uma oportunidade para subverter as agendas institucionais.

\section{Cinema colaborativo do Vídeo nas Aldeias e os Mbya-Guarani}

Durante a aplicação do INRC, algumas lideranças Guarani expressaram interesse em receber formação em realização cinematográfica, uma vez que consideram que só os Mbya sabem quando estes querem falar e ser filmados. Nesse sentido, o IPHAN-RS contratou a ONG Vídeo nas Aldeias (VNA), que há 30 anos desenvolve trabalho colaborativo com povos indígenas na área do audiovisual e que, desde 1997, organiza oficinas de formação de cineastas em aldeias indígenas. Como veremos, a introdução do cinema colaborativo reorganizou as relações intra e interétnicas, originando a emergência de novas lideranças, e expandiu a participação a outros atores que trouxeram novos dados para compreender as ruínas de São Miguel segundo a ontologia e cosmologia Guarani.

A primeira oficina decorreu em 2007, num primeiro momento na Tekoa Anhetengua e, a seguir, na Tekoa Koenju. Os formadores do VNA, Tiago Campos Tôrres e Ernesto Ignacio de Carvalho, encontraram-se em Porto Alegre (RS) com o Mbya-Guarani Ariel Ortega, que tinha viajado desde São Miguel. Sandro Ariel Duarte Ortega nasceu em 1985, em Missiones, Argentina, na Tekoa Vera Guaçu. O seu nome Guarani é Kuaray Poty, mas escolheu, como nome de cineasta, que também usa no Facebook, uma hibridização entre os dois: "Ariel Kuaray Ortega". Ortega é uma pessoa muito curiosa, como Tôrres explica:

o Ariel é um cara que se você começar a falar de Guerra Mundial, "Então, teve a Guerra Fria! Uai!" E tal. Um cara que tá interessado e faminto, com fome de mundo... Então é isso. O Ariel estava muito disposto para a bataIha e aí... a gente apresentando armas interessantíssimas. E ele pirou com essas armas. (Entrevista a Tiago Campos Tôrres, 11 de março de 2015)

Movidos por esta energia, Ortega, Tôrres e Carvalho chegaram à Tekoa Anhentegua em êxtase. Foram recibos pelo cacique Cirilo, que os reprimiu pela sua atitude "pouco Guarani" e que chegou a colocar em causa a realização da oficina. Segundo Carvalho,

[n]ossa chegada na aldeia foi explosiva. (...) Estávamos a 1000 por hora e ele [Cirilo] a 1. Se os Guarani são meditativos, contemplativos, filosóficos, o Cirilo nem se fala. Nos encontramos com ele e começamos a falar. Minha perceção de como este momento deveria ser conduzido era de explicar tudo o mais claro possível. Mas estávamos exaustos, fora de centro, elétricos e aquela foi a primeira experiência de colisão do jeito de ser Guarani e do jeito de ser branco. A maneira que se relacionam com o tempo e com a comunicação, com a conversa, com o silêncio, apesar de estarem incrustados no meio da cidade, é radical. Explicamos tudo ao Cirilo, da produção à edição, a importância do filme pronto, da nossa disposição para fazer o 
trabalho. Depois do Cirilo escutar essa explicação, esse desabafo afobado, ele nos disse de maneira simpática: "pois é, vocês brancos são muito diferentes da gente, vocês vão falando logo tudo. A gente não, somos diferentes, esperamos um pouco." Só então percebi o que estava acontecendo. E disse ao Cirilo: "vamos começar de novo". Voltamos para o carro, chegamos e começamos a conversar sobre se acomodar, montar as redes, dormir. (Carvalho citado em Carvalho, Carvalho \& Carelli, 2011, p. 138)

Segundo Ortega, a oficina foi muito difícil. A metodologia do VNA assenta numa aprendizagem prática, intensa e diária (normalmente durante três semanas). Após aprenderem os rudimentos básicos do manuseio da câmara, os formandos começam a filmar a aldeia numa abordagem de cinema direto. De modo a terem um foco, é frequente os formadores sugerirem que os alunos sigam uma personagem ao longo do dia. À tarde ou à noite, os formadores e os alunos veem e discutem o material gravado e planeiam as filmagens do dia seguinte. Esta interpelação imersiva ao real catalisa novos questionamentos e relações que podem originar resultados políticos significativos (Lacerda, 2018b).

Apesar do sucesso desta metodologia noutros contextos, num primeiro momento, a oficina quase fracassou. Em primeiro lugar, a maioria dos alunos aparecia e desaparecia e era difícil manter uma continuidade. Além disso, como já foi mencionado, os Guarani desconfiam de projetos que vêm do exterior, são passageiros e não costumam trazer retorno substancial para eles. A este nível, começou a gerar-se um ambiente de suspeição de que os alunos estariam a ser pagos, uma vez que o VNA estava presente com equipamento audiovisual dispendioso. Como Ortega explica: "nossa, foi muito difícil porque eu falava 'não, a ideia não é isso. É o dinheiro de salvaguarda e o IPHAN chamou eles, mas a ideia não é ganhar dinheiro ou dar dinheiro. Porque o filme vai ficar nosso, é de vocês'"'.

Tendo em conta este enquadramento, Ortega conseguiu convencer Tôrres e Carvalho a concluírem a oficina em Tekoa Koenju, algo que não fazia parte do plano inicial. Contudo, a situação nesta aldeia também se revelou difícil devido aos problemas já mencionados relativos à divisão política da aldeia e por Ortega não fazer parte da família extensa que dominava a relação da comunidade com os jurua. Após alguns dias de clima tenso, o cacique Floriano Romeu decidiu suspender a oficina e mandou expulsar os formadores do VNA. Esta resolução originou uma reunião geral da aldeia que se prolongou durante a noite. Por volta das três da manhã, comunicaram aos não indígenas que tinham substituído o cacique e que a oficina podia continuar.

Este processo intenso deu origem a mais de 100 horas de filmagem e ao primeiro documentário deste coletivo: Mokoi Tekoá Petei Jeguatá, duas aldeias, uma caminhada $(2008)^{10}$. O filme é divido em duas partes correspondentes às aldeias em que a oficina

\footnotetext{
9 Entrevista em Português a Ariel Kuaray Ortega, 10 de março de 2016.

${ }^{10} \mathrm{O}$ documentário foi exibido em diversos festivais nacionais e internacionais e foi premiado como melhor filme no Festival ForumDoc. $\mathrm{BH}$, em Belo Horizonte, no mesmo ano.
} 
teve lugar e apresenta a situação colonial" dos Mbya, rodeados por jurua e dependentes destes devido à exiguidade das suas terras e aspetos da espiritualidade daquele povo. $\mathrm{Na}$ segunda parte, a obra mostra a situação tensa dos Guarani a venderem artesanato nas ruínas e os discursos dos guias não indígenas que sublinham a missão "civilizadora" dos jesuítas e ignoram a contribuição e agência dos indígenas na construção das Missões e a presença dos Guarani contemporâneos. Como diz o Mbya Mariano Aguirre, no início desta sequência:

os brancos tiraram tudo da gente e se apropriaram dessas ruínas que nossos parentes fizeram. Agora eles não querem dar pra gente o que é nosso. (...) Nossos parentes construíram isso forçados pelos brancos, os padres Jesuítas. (...) Nossos parentes trabalharam, enfrentaram sofrimento, para deixar isso aqui na terra. Deixaram isso e trabalharam tanto para que depois os brancos os matassem todos. Os brancos brigaram por causa disso aqui. (...) Tudo isso é doloroso para nós. Se pensarmos, dói até hoje. (Aguirre citado em Morinico, Beñites \& Ortega, 2008)

Duas aldeias, uma caminhada foi um importante catalisador de discussões em diversas comunidades Guarani sobre a relação destes com as ruínas, contribuindo, assim, para o desenvolvimento do processo do $\mathrm{PCl}$. Alguns meses após a conclusão do filme, Ortega foi eleito cacique de Koenju, cargo que desempenhou até março de 2016 . O documentário seguinte, Bicicletas de Nhanderu (2011), sobre a espiritualidade Guarani, obteve ainda maior sucesso a nível nacional e internacional e é ainda hoje exibido em mostras de cinema indígena. Por outro lado, este filme iniciou o processo de afastamento entre Ortega e Cirilo devido ao facto de aquele trabalho cinematográfico mostrar as "festas brancas" da aldeia em que os Guarani, incluindo o karai, consumem álcool e jogam às cartas. Como explica Carvalho, "[a primeira] oficina e as outras que se seguiram colocaram Ariel no centro da discussão e como ator político, reconfigurou alianças, casamentos se fizeram e se desfizeram. O vídeo ali se inseriu na comunidade e na vida das pessoas, catalisando situações" (citado em Carvalho et al., 2011, p. 145). Assim, e como desenvolvo mais à frente, através do cinema e da colaboração com o VNA, Ariel Ortega tornou-se num importante ator no processo do $\mathrm{PCl}$.

\section{O PROCESSO DE REgisto do BEM CULTURAL TAVA}

Em 2007, o IPHAN organizou em São Miguel o "Encontro Internacional Valorização do Mundo Cultural Guarani" com o objetivo de responder à exigência dos Guarani de expandir o INRC a outros Estados do Brasil e países limítrofes. Concomitantemente, - IPHAN almejava que neste encontro fosse proposto pelos Guarani um bem cultural para ser registado enquanto $\mathrm{PCl}$. Essa fase do evento foi tensa e originou discussão entre as partes envolvidas, nomeadamente o IPHAN, a equipa do INRC e Cirilo. A desavença

\footnotetext{
"Compreendido neste contexto como "colonialismo interno" (Casanova, 1965) mas também enquanto "colonidade" (Quijano, 2010) no sentido de opressão e exploração política, económica, cultural e epistémica de grupos étnicos e/ou racializados por outros grupos dominantes com ou sem presença de administrações coloniais.
} 
só foi resolvida por via da intervenção dos Mbya mais velhos que, recorrendo à sua "fala mansa" (Pissolato, 2007), acalmaram os ânimos. Como resultado do encontro, um representante Guarani do Paraguai e 12 representantes de aldeias de seis Estados brasileiros (Rio Grande do Sul, Santa Catarina, Paraná, São Paulo, Rio de Janeiro e Espírito Santo) pediram o registo das ruínas de São Miguel enquanto $\mathrm{PCl}$ do seu povo.

Contudo, é importante frisar que não é clara a forma como a Tava foi selecionada enquanto elemento a ser registado. Tendo em conta conversas anteriores com os Guara$\mathrm{ni}$, os técnicos do IPHAN-RS pensavam que o ritual de nomeação nheemongarai seria a opção privilegiada. Apesar de esta cerimónia ser fundamental para o bom viver Guarani e se encontrar ameaçada devido à situação colonial, ela envolve a comunicação do karai com Nhanderu e, provavelmente, nunca foi intenção dos indígenas divulgar este processo. Por outro lado, segundo relatos coligidos pelo autor, cujas fontes não são identificadas por razões éticas, certos atores consideram que o IPHAN pressionou os Mbya a escolherem as ruínas, enquanto outros argumentam que foi a equipa do INRC que sugeriu esta ideia no sentido de afirmar os direitos territoriais daquele povo. De facto, as ruínas foram sempre um tema central e tenso durante o levantamento de referências culturais, acabando por se transformar num foco em que as principais causas Guarani se cruzam: a violência colonial exercida no passado e no presente; a expulsão do seu território e a quase ausência de processos de demarcação de terras; o racismo e, por outro lado, o romantismo e a apropriação colonial da sua imagem e história; mas também a importância de viver onde os seus antepassados moraram em busca da maturação corporal sem passar pela morte (aguyje). Este foco, desenvolvido através de encontros, palestras, filmes, entrevistas e até conflitos, propiciou a identificação ou, mais concretamente, a emergência das ruínas como síntese, não de uma cultura, mas de uma situação colonial passada e presente compreendida através da metafísica Guarani.

No seguimento do pedido de registo, o IPHAN-RS iniciou o processo de pesquisa no sentido de desenvolver o dossiê de candidatura. Devido a diversos fatores, o organismo estatal optou por, desta vez, contratar a ONG Instituto de Estudos Culturais e Ambientais (IECAM) em vez da UFRGS, que, por sua vez, estabeleceu contactos com a equipa de Catafesto de Souza. Após um ano de trabalho, a equipa regressou ao IPHAN com mais alguma informação relativa à Tava, mas o IPHAN-RS, dominado até então por técnicos com formação em arquitetura e história, portanto, sem um conhecimento antropológico necessário para os processos do $\mathrm{PCl}$, tinha finalmente contratado um licenciado em Ciências Sociais, Marcus Vinicius Benedeti, que se mostrou insatisfeito com a exiguidade, dispersão e não enquadramento teórico e cosmológico dos testemunhos recolhidos.

Neste contexto, o IPHAN-RS voltou a contratar o VNA no sentido de este produzir o filme de documentação que também foi parte constitutiva e essencial da pesquisa. $O$ trabalho final, Tava, a casa de pedra (2012), é assinado pelos não indígenas Vincent Carelli e Ernesto Carvalho e pelos Mbya-Guarani Ariel Ortega e Patrícia Ferreira e centra-se em entrevistas com velhos de aldeias de Rio Grande do Sul, São Paulo, Rio de Janeiro e Argentina. A participação de Ortega foi fundamental porque, além de ser um Guarani carismático que sabe ouvir e falar com os mais velhos, ele também é neto de um dos mais 
importantes caciques da Argentina, Dionísio Duarte, que todos os Mbya conhecem. Sem dúvida, este foi um cartão de visita fundamental para obter os vários depoimentos sobre as ruínas que eram largamente desconhecidos dos não indígenas e até de uma parte significativa dos Guarani. Por outro lado, em entrevista realizada pelo autor, Cirilo foi muito crítico em relação a esta abordagem de Ortega por este ter violado a "dimensão do segredo". Segundo aquele, os cineastas deviam ter primeiro discutido com as lideranças e não ter divulgado a polifonia de interpretações dos Guarani sobre as Missões.

A riqueza do material obtido durante a produção do documentário conferiu mais confiança ao IPHAN-RS que avançou para a elaboração do dossiê de registo da Tava. A pedido deste, o dossiê foi redigido por Sílvia Guimarães, que tinha realizado a pesquisa de mestrado com uma comunidade Mbya-Guarani em Espírito Santo e que, naquela altura, trabalhava na Coordenação de Registo do Departamento de Patrimônio Imaterial do IPHAN central. Nesse sentido, a antropóloga combinava um conhecimento etnológico significativo e uma experiência burocrática relevante sobre o trâmite dos processos de registo. Guimarães não recebeu qualquer vencimento por este trabalho, mas, como contou ao autor em entrevista, sentiu que o devia realizar por possuir uma "dívida histórica" com os Guarani, uma vez que graças a eles possuía uma carreira profissional. Antes de começar a redação, a antropóloga aproveitou um encontro da CGY que reuniu vários representantes Guarani em Koenju para confirmar se estes estavam de acordo com o processo de patrimonialização. Após a aprovação destes, a antropóloga Sílvia Guimarães redigiu o trabalho recorrendo preferencialmente aos depoimentos recolhidos pelo VNA e utilizando a pesquisa do seu mestrado como suporte teórico. Quando chegou perto de uma versão final, regressou a Koenju e reuniu com a kunha karai, com mediação linguística e cultural de Ariel Ortega e Patrícia Ferreira, no sentido de verificar a validade da sua argumentação e de retirar algumas dúvidas etnológicas. Por fim, Guimarães e o IPHAN-RS reuniram com a aldeia com o intuito de determinarem o nome oficial do bem cultural. Durante o processo de pesquisa, especialmente devido aos depoimentos recolhidos no documentário Tava, a casa de pedra, tinha sido decidido que o termo tava era mais consensual do que tava miri, uma vez que estas são perfeitas e imperecíveis (miri) e, portanto, só existem nas moradas dos deuses. Como explica o Mbya Mariano Aguirre no filme supramencionado, "Tava miri a gente não vê, porque não fica nessa terra. Ela está onde a gente vê os raios. Essa tava é uma tava imperfeita, que a gente vê" (Aguirre citado em Ortega, Ferreira, Carvalho \& Carelli, 2012). Além disso, um dos presentes na reunião lembrou que os subgrupos Ñandeva e Kaiowá também visitam as ruínas e foi decidido utilizar o etnónimo abrangente Guarani em vez de nomear o bem cultural exclusivamente Mbya. A designação acordada foi "Tava, lugar de referência para o povo Guarani".

Por fim, a 3 de dezembro de 2014, o Conselho Consultivo reuniu na presença de elementos do IPHAN-RS, mas também de Ariel Ortega, Patrícia Ferreira e outros representantes Mbya-Guarani. Apesar de alguma controvérsia, o registo foi aprovado por unanimidade. Assim, após um processo de dez anos, em dezembro de 2014, as Missões Jesuítico-Guarani foram registadas no Livro de Lugares do $\mathrm{PCI}$. No final da reunião, Ortega pediu para fazer uso da palavra: 
primeiramente, agradecer por esse lindo momento. Eu acho que falo em nome de toda a comunidade da minha aldeia, de todos os meus avós que, meus ancestrais que viveram ali nas reduções jesuíticas. Não tenho dúvida que eles estão presentes aqui, nos acompanhando. Eu acho que é o momento muito importante para os nossos netos, os meus netos, futuras gerações para todo o guarani, porque é importante esse reconhecimento para a gente (...) porque hoje em dia a gente tem somente 234 hectares em São Miguel das Missões, quando antes o vasto território era todo nosso. Agradeço muito a Nhanderu por esse momento, por iluminar cada um de vocês, Conselho. Eu tenho a certeza que todos os Caraí, os líderes espirituais também estavam meditando para esse momento acontecer. Então quero agradecer por esse momento, obrigado. (IPHAN, 2014, p. 74)

\section{Avaliação do processo pelos Guarani}

As consequências concretas deste processo para os Guarani parecem ser, pelo menos por enquanto, pouco palpáveis. Em entrevista realizada pelo autor ${ }^{12}$, Cirilo advogou que o mais importante é que a patrimonialização ajudou a provar que os Guarani têm direito ao seu território tradicional e que eles não são "estrangeiros", "argentinos" ou "paraguaios", como diversas pessoas e até instituições, inclusive alguns dentro do IPHAN, os denominam. Por outro lado, criticou que a Tava não tenha sido reconhecida como Património da Humanidade'3. Nesse sentido, é possível argumentar que a interpretação não indígena das Missões a nível da Unesco possui um maior poder simbólico do que a patrimonialização Guarani das Missões apenas a nível nacional. Além disso, Cirilo lamentou que o INRC não tenha tido continuidade e que não tenha aprofundado outros elementos do património Guarani, como a cerâmica, que o seu filho hoje em dia ensina na escola da aldeia.

Uma das exigências dos Mbya de Tekoa Koenju e de Cirilo é que eles possam trabalhar como guias no Sítio Arqueológico. Como este explica, "[d]everia ser os próprios indígenas a trabalhar ali para poder... Fica mais lindo assim, né? Um índio Guarani falar sobre a sua história"14. Esta proposta não está relacionada com um regime de propriedade porque "[e]u acho que tem de ter liberdade"15. O principal entrave parece ser que os guias têm de fazer um curso no Ministério do Turismo com um custo proibitivo para os Mbya. De facto, a medida do plano de salvaguarda escolhida pelos Guarani para 2016 foi uma oficina de turismo, em vez da produção de um livro bilingue para distribuir pelas escolas indígenas e não indígenas do Estado, como o IPHAN esperava com base em conversas anteriores.

\footnotetext{
${ }^{12}$ Entrevista em Português a José Cirilo Morinico, 7 de abril de 2016.

${ }^{13} \mathrm{~A}$ título de exemplo, a "arte kusiwa, pintura corporal e arte gráfica Wajãpi", e o "ritual yaokwa do povo Enawenê-nawê" foram classificados como Património Cultural Imaterial da Humanidade, pela Unesco, após o seu registo a nível nacional pelo IPHAN.

${ }^{14}$ Entrevista em Português a José Cirilo Morinico, 7 de abril de 2016.

15 Entrevista em Português a José Cirilo Morinico, 7 de abril de 2016.
} 
Outra das exigências dos Mbya é que parte dos ingressos nas ruínas reverta para "a comunidade". O IPHAN e a Prefeitura (proprietária do Espetáculo de Som e Luz) não se opõem, mas aquele adverte que as receitas não conseguem sequer financiar os custos de gestão do Parque Arqueológico e que não existe enquadramento legal para transferir estas verbas. Em alternativa, propõe utilizar aquela percentagem em projetos comunitários. Além disso, é importante relembrar que o Brasil atravessa uma profunda crise política e económica e que o futuro do financiamento do plano de salvaguarda - e até do IPHAN - é incerto.

Entretanto, num processo paralelo, em maio de 2015, as Missões Jesuítico-Guaranis, Moxos e Chiquitos foram declaradas Património Cultural do Mercosul (PCM) ${ }^{16}$. Esta categoria foi criada em 2012 como parte do Mercosul Cultural e tem por objetivo fortalecer a cooperação e a integração dos países através da identificação, conservação e promoção de património que seja partilhado por mais de um dos países. O sítio do IPHAN ${ }^{77}$ sobre esta patrimonialização centra-se na história ocidental e/ou jesuítica, não fazendo qualquer menção à relevância das Missões para os Guarani atuais. Porém, no "XVII Encontro da Comissão do Patrimônio Cultural do Mercosul", a 30 e 31 de outubro de 2018 , respondendo às exigências dos representantes Guarani, a Mercosul reconheceu a Tava como Patrimônio Cultural da Mercosul, significando

o reconhecimento da presença ancestral dos Guarani no território Yvy Rupá, que hoje integra o Brasil, a Argentina e o Paraguai, no qual organizaram uma grande rede étnica, formada por aldeias, caminhos e locais sagrados. Transitar livremente por esse território, como fizeram seus ancestrais, os antigos, é um dos fundamentos do bem-viver que os Guaranis desejam preservar. ${ }^{18}$

\section{CONCLUSÃo: PATRIMÓNIO DIALÓGICO}

Num primeiro momento, o estudo de caso de patrimonialização das ruínas de São Miguel confirma a importância da participação de grupos, comunidades e "especialistas" não científicos na identificação do $\mathrm{PCl}$. Apesar de a bibliografia sobre os Guarani ser uma das mais extensas dos povos ameríndios da América do Sul, a diferente ontologia e a importância cosmológica das ruínas para aquele povo eram praticamente desconhecidas dos não indígenas e até de alguns Guarani'19. Esta compreensão só foi possível através da participação empenhada de elementos deste povo no processo de pesquisa e através

\footnotetext{
${ }^{16}$ Mercosul refere-se ao Mercado Comum do Sul, uma organização intergovernamental fundada em 1991 que inclui Argentina, Brasil, Paraguai, Uruguai e Venezuela (atualmente, suspensa). A Bolívia aguarda trâmites burocráticos para se tornar membro de pleno direito. As línguas oficiais são o português, espanhol e guarani (proposta pelo Paraguai mas ainda pouco adotada institucionalmente). No início, o Mercosul era principalmente uma união aduaneira dentro da qual há um regime de livre comércio e uma política comercial comum, mas a sua área de atuação tem vindo a expandir-se.

${ }^{17}$ Retirado de http://portal.iphan.gov.br/uploads/ckfinder/arquivos/Decis\%C3\%A30\%20MERCOSUL.pdf

${ }_{18}$ Retirado de http://portal.iphan.gov.br/rs/noticias/detalhes/4883/lugar-de-referencia-para-o-povo-guarani-pode-se-tronar-patrimonio-cultural-do-mercosul

19 Existiam, contudo, já alguns indícios em Ladeira (1992/2007).
} 
do reconhecimento dos benefícios que estes podiam obter para as suas lutas, especialmente a nível da demarcação das terras. Nesse sentido, é importante sublinhar que a participação dos Guarani só foi viabilizada através de uma hibridização estratégica entre os modos de fazer política indígenas e não indígenas, incluindo a antecipação de diversas medidas de salvaguarda e da formação de pesquisadores e realizadores indígenas, de modo a estabelecer, segundo a lógica ameríndia, graus de afinidade (Castro, 2002a) entre os agentes indígenas e não indígenas. Algumas destas relações já existiam (por exemplo, entre Catafesto de Souza e Cirilo devido às atividades promovidas em conjunto com a UFRGS), enquanto outras foram produzidas durante o processo, mas com alguma distância em relação ao órgão governamental (por exemplo, entre Ariel Ortega e o VNA). É ainda interessante ressaltar que as conexões não se estabeleceram unicamente dentro das fronteiras étnicas, mas também através de diferentes alianças interétnicas.

Contudo, como Harrison defende na sua proposta de um "património dialógico", este não emerge apenas das relações entre humanos (especialistas científicos e não científicos), mas também por meio de conexões com não humanos e coisas. No estudo de caso em análise, a ação dos Guarani é determinada pelos deuses (Schaden, 1974). Tudo aquilo que acontece é decidido pelos deuses e os Guarani tentam compreender as deliberações daqueles por meio do sonho, canto-reza, belo caminhar e outras práticas estético-éticas de corporalidade, comensalidade e convivialidade. Um dos exemplos enunciados foi o sonho que Cirilo teve com o Nhanderu Miri Sepé Tiaraju e que o levou a decidir apoiar o processo do $\mathrm{PCl}$. Do mesmo modo, o discurso de Ariel Ortega no final do Conselho reconhece que o sucesso do processo só se deveu à intervenção de Nhanderu. Segundo este enquadramento, o processo de patrimonialização só foi viabilizado através da influência de pessoas não humanas.

Além disso, o próprio valor histórico e simbólico das ruínas de São Miguel teve influência na sua transformação em património. Por um lado, segundo a Constituição da modernidade, as ruínas são uma das arenas mais evidentes da ferida colonial Guarani, uma vez que estes, devido à exiguidade das terras compradas ou demarcadas pelo Estado, se veem obrigados a sobreviver através da venda de artesanato aos jurua, que, por sua vez, os discriminam e os classificam como "aculturados" ou "estrangeiros" ("paraguaios" ou "argentinos"). Este foco de tensão contribuiu para a emergência das ruínas como síntese, não de uma cultura, mas de uma situação colonial passada e presente. Segundo esta perspetiva, a patrimonialização das ruínas enquanto Tava é um reconhecimento estatal da relação histórica dos Guarani contemporâneos com aquelas estruturas e, implicitamente, do seu direito à demarcação de terras indígenas. Por outro lado, de acordo com a ontologia Guarani, as ruínas não são apenas estruturas físicas inertes. A Tava assinala onde os antigos Guarani viveram no seu caminho para a Terra sem Males e, portanto, é um lugar escolhido por Nhanderu para o bom viver deste povo. Nesse sentido, as ruínas não são apenas um objeto do passado, mas um lugar onde o passado se dobra sobre o presente e onde os Guarani podem encontrar indícios dos deuses para alcançar o estado de maturidade corporal (aguyje) de modo a chegar à morada celeste imperecível. 
Por fim, o cinema e a câmara de filmar também foram participantes do processo de patrimonialização. A câmara não foi utilizada para apenas representar uma realidade pré-existente, mas instigou reações e conexões, nomeadamente na relação com os turistas nas ruínas em Duas aldeias, uma caminhada e na pesquisa levada a cabo entre Guarani de diversas aldeias do continente sul americano, que, por sua vez, originaram discussões que resultaram no registo das ruínas enquanto Tava. Como profere o velho sábio Adolfo Werá Silveira em Tava, a casa de pedra: “já que estão filmando, vou dizer a verdade" (Silveira citado em Ortega et al., 2012).

Em suma, apesar dos momentos pontuais de dissonância inerentes a estes processos, a patrimonialização da Tava constituiu uma experiência importante na expansão dos conceitos de património e de participação em que os vários intervenientes não indígenas "levaram a sério" (Castro, 2002b) a ontologia e a cosmologia Guarani, originando um "fórum híbrido" (Harrison, 2013) em que humanos, não humanos e coisas participaram de modo a constituir uma democracia mais dialógica que tem em consideração diferentes modos de construir o mundo. O desafio agora, como sublinham os depoimentos de Cirilo e Ortega, é continuar este processo e integrar esta nova perspetiva construtivista e abrangente da participação na gestão do IPHAN e, especificamente, do Parque Arqueológico de São Miguel.

\section{Agradecimentos}

Pesquisa financiada pela Fundação para a Ciência e Tecnologia (FCT) com referência PD/BD/52265/2013, no Centro em Rede de Investigação em Antropologia (CRIA), com referência UID/ANT/04038/2019.

\section{REFERÊNCIAS}

Ashworth, G. J. \& Turnbridge, J. (1996). Dissonant heritage: the management of the past as a resource in conflict. Chichester: Wiley.

Ashworth, G. J., Graham, B. \& Turnbridge, J. (2007). Pluralising pasts: heritage, identity and place in multicultural societies. Londres: Pluto Press.

Batista, J. (2015). Dossiê Missões: as ruínas. Brasília: IBRAM.

Blake, J. (2009). Unesco's 2003 Convention on intangible cultural heritage: the implications of community involvement in "safeguarding". In L. Smith \& N. Akagawa (Eds.), Intangible heritage (pp. 45-73). Londres/Nova lorque: Routledge.

Bortolotto, C. (2014). La problemática del patrimonio cultural inmaterial. Culturas. Revista de Gestión Cultural, 1(1), 1-22. https://doi.org/10.4995/cs.2014.3162

Carvalho, A., Carvalho, E. I. de \& Carelli, V. (2011). Vídeo nas aldeias: 25 Anos. Olinda: Vídeo nas Aldeias.

Casanova, P. G. (1965). Internal colonialism and national development. Studies in Comparative International Development, 1(4), 27-37. 
Castro, E. V de. (2002a). A inconstância da alma selvagem e outros ensaios de Antropologia. São Paulo: Cosac Naify.

Castro, E. V. de. (2002b). O nativo relativo. Mana, 8(1), 113-48.

Clastres, P. (1974/2013). A sociedade contra o Estado: pesquisas de antropologia política. São Paulo: Cosac Naify.

Cooke, B. \& Kothari, U. (2002). Participation: the new tyranny? Londres/Nova lorque: Zed Books.

Cunha, M. C. da. (2008). "Culture" and culture. Traditional knowledge and intelectual rights. Cambridge: Prickly Paradigm Press.

Ganson, B. (2003). The Guaraní under Spanish rule in the Río de la Plata. Stanford: Stanford University Press.

Handler, R. (1988). Nationalism and the politics of culture in Quebec. Madison: The Wisconsin University Press.

Harrison, R. (2013). Heritage: critical approaches. Oxon/Nova lorque: Routledge.

Herzfeld, M. (1991). A place in history: social and monumental time in a Cretan town. Princeton: Princeton University Press.

INRC - Inventário Nacional de Referências Culturais. (2006). Relatório da etapa de identificação sítio comunidade Mbyá-Guarani São Miguel Arcanjo. Porto Alegre: IPHAN/RS \& NIT/UFRGS.

IPHAN. (2014). Ata da $77^{a}$ Reunião do Conselho Consultivo do Patrimônio Cultural - Brasília - 03 e o4 de Dezembro de 2014. Retirado de http://portal.iphan.gov.br/uploads/atas/ATA_77_Reuniao_Conselho_ Consultivo_03_e_04122014.pdf

Lacerda, R. (2018a). O plano, o contraplano e o "plano sem plano": imagens ocidentais e os Mbya Guarani das Ruínas de São Miguel. Iluminuras, 19(46), 135-168. https://doi.org/10.22456/1984-1191.85245

Lacerda, R. (2018b). The collaborative indigenous cinema of Vídeo na Aldeias and the intangible cultural heritage. MEMORIAMEDIA, 3, 1-11.

Ladeira, M. I. (1992/2007). O caminhar sob a luz: território Mbya à beira do oceano. São Paulo: Editora UNESP.

Milne, E-J. (2012). Saying "no" to participatory video: unraveling the complexities of (non) participation. In E-J Milne, C. Mitchell \& N. de Lange (Eds.), Handbook of participatory video (pp. 257-268). Plymouth: Altamira Press.

Moraes, C. E. N. (2010). A refiguração da Tava Miri São Miguel na memória coletiva dos Mbyá-Guarani nas Missões/RS, Brasil. Tese de doutoramento, Universidade Federal de Rio Grande do Sul, Porto Alegre, Brasil.

Morinico, J. R., Beñites, G., Ortega, A. (Realizadores). (2008). Mokoi Tekoá Petei Jeguatá, Duas aldeias, uma caminhada [Filme]. Brasil: Vídeo nas Aldeias.

Noyes, D. (2006). The judgment of Solomon: global protections for tradition and the problem of community ownership. Cultural Analysis, 5, 27-56.

Ortega, A. \& Ferreira, P. (Realizadores). (2011). Bicicletas de Nhanderu [Filme]. Brasil: Vídeo nas Aldeias.

Ortega, A., Ferreira, P., Carvalho, E. I. \& Carelli, V. (Realizadores). (2012). Tava, a casa de pedra [Filme]. Brasil: Vídeo nas Aldeias.

Pierri, D. (2018). O perecível e o imperecível: reflexões Guarani Mbya sobre a existência. São Paulo: Elefante. 
Pires, D. de M. (2007). Alegorias etnográficas do Mbya rekó em cenários interétnicos no Rio Grande do Sul (20032007): discurso, prática e holismo Mbyá frente às políticas públicas diferenciadas. Dissertação de mestrado, Universidade Federal de Rio Grande do Sul, Porto Alegre, Brasil.

Pissolato, E. (2007). A duração da pessoa: mobilidade, parentesco e xamanismo Mbya (Guarani). São Paulo: Editora da UNESP.

Quijano, A. (2010). Coloniality and modernity/rationality. In W. D. Mignolo \& A. Escobar (Eds.), Globalization and the decolonial option (pp. 22-32). Oxon/Nova lorque: Routledge.

Rose, D. (2011). Wild dog dreaming: love and extinction. Charlottesville/Londres: University of Virginia Press.

Schaden, E. (1974). Aspectos fundamentais da cultura Guarani. São Paulo: Editora da Universidade USP.

Smith, L. (2006). Uses of heritage. Oxon: Routledge.

Souza, J. O. C. (1998). Aos fantasmas das Brenhas: etnografia, invisibilidade e etnicidade de alteridades originárias no sul do Brasil. Tese de doutoramento, Universidade Federal de Rio Grande do Sul, Porto Alegre, Brasil.

\section{NotA BIOGRÁFICA}

Rodrigo Lacerda é investigador do Centro em Rede de Investigação em Antropologia (CRIA) do polo da Faculdade de Ciências Sociais e Humanas da Universidade Nova de Lisboa (NOVA FCSH) e coordenador do Núcleo de Antropologia Visual e da Arte (NAVA) do CRIA. Professor Auxiliar Convidado do Departamento de Antropologia da NOVA FCSH em 2017 e 2018.

ORCID: https://orcid.org/oooo-0002-6297-4682

Email: rodrigofernandes@fcsh.unl.pt

Morada: Universidade Nova de Lisboa, Avenida de Berna, 26-C / 1069-061, Lisboa, Portugal

* Submetido: 31/01/2019

* Aceite: 08/05/2019 